Article

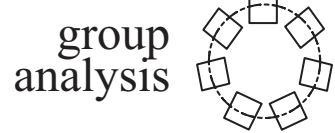

\title{
The internal group space
}

\author{
Michael Scott (ID and John Walshe
}

In this article we describe dynamic structures and relationships that arise in the internal space of groups, a space which materializes from the unconscious internal world of each group member and within the group as a whole. We use keys and doors as metaphors to explicate our understanding of the internal dynamics. We give examples of how these metaphors can be used to understand the structure, the function and the relationships within the group. The possible connections of these ideas to other theoretical frameworks are discussed.

Key words: internal space, doors, keys, symbol formation, metaphor, psychoanalysis, group analysis

\section{Introduction}

Our view is that the awareness of symbols, metaphors and play are central in understanding the structure and function of groups and organizations. In this article we use keys and doors as metaphors to aid our description of the dynamics and relationships of the internal space, that is, a space which materializes and becomes apparent when individuals gather and form a group. The internal space can be visualized as a place where there are many doors which can be opened by the group and the keys for the doors are found in the events and dynamic relationships within the group. These doors which may have a label on them, conceal the spaces that when opened by the members can provide insight and knowledge leading to particular ideas, thoughts and feelings.

(C) The Author(s), 2020. Article reuse guidelines: sagepub.com/journals-permissions 1-15; DOI: 10.1177/0533316420951729

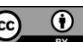


Particular doors are more overt depending upon the function of the group and the particular needs and personalities of the group members. We propose that the opening of doors can develop and enlarge the space over time. They can, when opened, contribute to the central space of the group by leading to a greater understanding and increase in the healthy functioning of the group but sometimes, also, opening a door can divert or diminish that function.

There are often labels on the doors which have recognizable schools of thought about how the space inside them functions, leading to relationships and feelings within that can be understood in many ways including Kleinian symbolic terms, (Klein, 1930) and (Segal, 1957), Winnicott's developmental metaphors (Winnicott, 1971), Derrida's sense of play, (Derrida, 1967) and the pattern of individuals' response to their symbolic developmental experience (Lacan, 1977). It is possible that the idea of a matrixial nodal point (Foulkes, 1971) could be expanded or understood by considering that each nodal point is a metaphorical door. We understand Foulkes' nodal points as the themes recurring within the group interconnected within a matrix of unconscious thoughts and feelings.

The importance of whether a door should be opened or not will depend upon the group function. We think that there are choices as to which door is opened and the choice can be essential to the working of the group. The choice is probably best guided by the principle of trying to open the door to the activity or process that is perceived to be most conscious.

We have found that in training other therapists and in our own experience as therapists the metaphor of doors and keys to open them has an explanatory power which illuminates the dynamics of a group. We make use of these metaphors to ask questions like: Who has opened or is opening the door? Why open the door? Which door to open? When would it be best to do so? What key to use at any moment? There is no absolute answer to these questions but to be able to ask them and to discuss and illustrate possible answers can be very effective.

Our reflections on the internal space are informed by a psychoanalytic and group analytic perspectives. In this article we also consider other factors which include behavioural, social and conscious mechanisms. We think these factors always affect the space inside and outside the group even if the purpose of the group is psychoanalytical.

Our psychoanalytic view is eclectic in that we think that unconscious mechanisms can be best understood and described by using a 
multiplicity of psychoanalytical concepts. In the past there have been arguments between different therapeutic schools about whether some concepts are present or about their degree of importance in groups. Psychoanalytic and organizational theorists have gone as far as to insist that their ideas alone are to be considered. Our view is that the features we outline are present in all groups. We suggest in this article that they vary in importance and can be more or less significant depending upon the type, the development and the function of the group. We think that it is of primary importance to use the dynamics and processes of the group itself and not some ideological framework imposed from the outside or from the therapist. For example:

A mature analytic psychotherapy group were discussing feelings and ideas relating to neediness and being cared for. The analyst tried to open a Kleinian door about the need the group has for more feeding, perhaps a good breast, the group members told the analyst that they understood this and he was therefore wasting their time and space! In part rejecting the need for total dependency saying 'we are capable of working things out for ourselves'.

We hope to describe briefly our understanding of what and how one can make use of these metaphors. We give examples of how they work practically in groups and an example of a particular therapeutic group session. In this process we refer to previous ideas by other individual, group and organizational theorists.

We propose to divide the article under three different headings.

1. Doors commonly observed in groups.

2. Different groups, different functions, different doors.

Some doors tend to be more present, more obvious and more prevalent, depending upon the group's function.

3. Discovering the key for the door.

How does one find and recognize the key to the door? A key which is present in the space.

\section{Doors commonly observed in groups}

We outline below some of the common doors that may be visualized in a group space and give an example of a particular group session 
delineating different doors that were opened from the conductor's perspective over one and a half hours. We realize that the examples do not cover all the possibilities that were present and different doors can be associated with different theoretical positions. To become aware of which door is opening is an important issue for a functioning group and part of the work of a group leader is to be sensitive to this process.

\section{The entrance door}

The label on the entrance door of any internal space can be understood as its work function (Bion, 1985). The space inside this door is where the members gather together to consciously carry out an agreed function, purpose or intention. It is the overt reason for the meeting of the group. It is important in understanding what is occurring in the group space to monitor and keep in mind the agreed intention. Many groups tend to wander away from the stated purpose on their entrance door and do not focus on the agreed work. Monitoring the boundaries of the group is essential, see (Walshe, 1995).

People may become defensive or even leave because they have not been sufficiently informed of the function of the group. It is essential to explain what the group is for. In this we have found it helpful to state the purpose of the group in writing and speaking directly to the members before joining a group. The label on the door ought to be written in large capitals.

In this particular example the members of this group knew that its function was to consider unconscious motivations in their lives. A function which they sometimes avoided and, on this occasion, it occurred at the beginning.

All the group members have arrived on time except for a man in his late 20s who tends to arrive late, which had been commented on several times in previous sessions. He is 15 minutes late.

\section{The social door}

This is a door about the social life of the members. Opening this door evades the main function of the group particularly if it lasts through out the group.

The group began by talking about the weather, it had been snowing so this was an obvious social door to open. They commented on previous experiences of snow and the accidents that had happened to them and other people. They wondered about the whereabouts of the man who had not arrived yet. They asked: Was he caught in the snow? 
They mentioned that he is quite often late! They expressed worry about his absence leading to another door about feelings of loss and separation.

\section{Separation, loss, anxiety door}

This is a common door in therapeutic groups which in this case rose from the absent member.

The man arrives and immediately somehow takes up the theme of separation, an example of how unconscious themes seem to be present in the matrix of a group (Foulkes, 1971) and talks about having difficulty in finding a job, not enough money to get a place by himself and how his mother would have difficulty in looking after herself if he left. He expresses feelings about how he might leave home. He says that he has nowhere to go. He says that his mother would 'collapse' if he left home.

The conductor saw this as an anxiety about separation and attachment (Bowlby, 1977) with Freudian oedipal overtones of separation from mother and parental authority (Freud, 1910 ). The conductor noted that the man did not offer an excuse for his lateness and also noted, becoming conscious of his own feelings, that he himself had tended to look upon this 27 year-old man as just a boy, a young teenager!

Once this separation door is opened other members begin to participate in this space.

One woman describes her own country as the best country in the world but feels she cannot go back. There are Bowlbian questions of attachment and loss here but also another door about questions of identification. (See identification door.)

Another woman talks about not being able to let go of her baby and how she was not able to go down the stairs holding the baby 'for fear of falling' [separation and loss].

When they were talking about the young man's lateness, they said he should be here! 'Why can't he come on time?' (the authority door).

\section{The authority, family, parental door}

This is a door within which questions about parental, sibling relationships arise, the oedipal complex (Freud, 1923) including the transferential relationship to the conductor.

An older woman speaks about memories of her father as an alcoholic but she was never able to be angry with him. 
A younger woman begins to cry about the death of her father for the first time. He had died 10 years previously (Bowlby, 1978).

The man who arrived late talks about his envy of his sister coming to the family home and the authority she has over her mother.

A woman explains how she could not choose potatoes that her mother would not approve of in a supermarket. She became angry with herself and she left the supermarket in anger and frustration without buying anything.

These are illustrations of the power of parental authority and how our defences can sometimes stop us from achieving even simple everyday tasks and needs (Freud, A, 1937).

\section{Paranoid-schizoid and depressive position door}

This door is almost invariably about feelings relating to the outside world and situations within the group. The dynamics in a group relating between the inside and outside are essential to note (Walshe, 2006).

The woman who saw her country as the best place and England was 'rubbish'. The space that this opens up is similar to the Kleinian positions of paranoia and depression (Klein, 1946). The world is a dangerous place. A man talks about the group being much better than the outside. Here he says we are able to talk about things but nobody will listen to what we have to say outside of the group.

A woman admitted that she never told anyone that she was married including all her friends in her local village. This also could be understood as a door into the power of the social, and Fromm's view of social relationships (Fromm, 1965). The feelings and ideas in this space tend to be fixed, not logical and difficult to change.

\section{The identification/persona door}

A door linked to questions of what would the neighbours think? Who is looking at me?

The young man when asked by the group what was it that made it very difficult to leave his mother? Part of his reply included the idea that he did not see himself as separate from her. Is this an over identification with the mother? A lack of self-image? Doubts about who he is?

A series of exchanges arose in the group when a woman made a comment about her hair style, saying it was not quite right. This led to another man talking about getting himself out there but worries 
how people will see him. He says 'for me it is like having a red card in my head all the time'.

All of these exchanges could be seen through Lacanian theories about image and how we see ourselves (Lacan, 1977).

There were thoughts about the possibilities of the use of different persona 'acting not like ourselves' (Jung, in Read et al., 1954).

After the woman talked about her hair style other members of the group took up the theme of how they presented themselves to the world. Another woman said that she was always a business woman and did not have enough energy to be herself.

\section{Existential door}

Quite often in the group space the question of our existence prevails. What are we here for? What is the point? In what way and why do we exist? Everything is uncertain. How do we relate to the world? As one man said, 'I prefer to play tennis with myself'.

These are important feelings about how we are ultimately alone, that death is inevitable and that we must take responsibility for ourselves-existential themes that Yalom believed were curative when expressed (Yalom, 1975).

\section{Different groups, different functions, different doors}

There are doors that are more likely to appear in particular types of groups or organizations. They tend to be linked to their function, their raison d'etre.

We think that it is important to be aware of this because difficulties can arise if the wrong door is opened in a space where it does not match with the function of the group. It can be disastrous to the group function if an attempt is made to open an interpretative group psychoanalytical door when the group is operating at another level.

An example of this problem:

A therapist was attending a working group of nurses whose function was to consider changes in the management system. She began to comment (open doors) about the need for the members to find a scapegoat for their frustrations and that certain members were more dominated by their superegos. In supervision it was noted that although the therapist's interpretation had some veracity it was not helpful to open these doors, given that the main function of the group was to consider the management system and not the internal dynamics of the group or the individual members. Unfortunately 
the therapist persisted in opening these doors and the group became more dysfunctional and did not produce anything of value.

The following are examples of doors that tend to be prevalent in different groups.

\section{a. Groups organized to carry out a function external to the group}

Examples of this type of group or organization would be pressure groups, political groups, manufacturers, marketing groups et al.

These groups can be understood as work groups in Bion's sense of the work group (Bion, 1985). There is usually an overt agreement as to their purpose and intentions.

The doors that are likely to be present in these groups tend to open into unconscious spaces where Bion's basic assumptions of fight or flight and pairing operate. They can pursue a culture of 'we are the best', and 'those outside have no idea how good we are or what we are capable of'. These kind of belief systems lead to depressive and paranoid feelings of an unconscious Kleinian nature, opening doors which overwhelm the effectiveness of the organization.

For example: The family manufacturers who continue to produce the same widget or follow a particular system for generations and insist on doing so despite the fact that the system no longer works and the widget is not marketable. They are close to the paranoid world of isolation, ritual behaviour, and psychotic relations with the environment with which they would have had real transactions in the past, but now increasingly blame external circumstances and denying the reality of the situation (Menzies, 1959). Their response is that 'people are stupid not to buy what we sell' and that there is something wrong with the outside world.

\section{b. Groups that are formed to deal with external forces or demands}

These are generally universities, schools, NHS hospitals. There are many government, societal demands and constraints on these institutions. Their bureaucracies and their front-line workers are under constant pressure from the needs of pupils, patients on one side and the Government on the other. In these institutions one can find doors leading to spaces dealing with anxieties surrounding death, the subject's future and powerful feelings of dependency and existential angst. The basic assumption dependency outlined by Bion (Bion, 1985) and the existential factors of (Yalom, 1975) are ever present 
doors within these organizations, often using social defence systems against these anxieties described by (Menzies, 1959).

\section{c. Groups that meet to use the group itself}

There is a long list of different types of such groups. They include groups for helping, informing, invigorating the group members themselves. They go from the overtly social to in depth exploration of the unconscious. The overtly social doors that can be opened are probably best summarised by the curative factors of Yalom (Yalom, 1975). Cohesiveness, development of socializing techniques, imparting of information would be significant in these social groups. If the label on the door is for in depth unconscious exploration, that is to analyse oneself or to analyse and learn about groups, then all the group analytical doors referred to above are likely to become visible.

Both (a) type and (b) type groups usually have some say in how the external force operates on them or how they, the group or organization are going to go about dealing with the external world. They often create a huge bureaucracy to deal with this. Whereas (c) type groups do not have the external pressure but generate their own internal anxieties.

\section{Discovering the key for the door}

Keys can be understood as particular observations of what is happening in the group itself. They generate pinpoint observations and questions i.e. questions about how one might find the key? What keys should one use? and how and what door to open? Several instances like these keys were pointed out by Foulkes (1964).

We give examples below of what we think of as keys,

\section{(i) Attendance key}

This key is about not attending, coming late or sending messages to the group. We have found if a member leaves a message it is helpful to put it in writing.

It is usually significant especially if there is a repetitive pattern to it.

Members' ways of attending may be something to do with the individual or a defence against the function of the group e.g.

a. members coming early. Single individuals coming early using a key that opens the door which shuts out anxiety. 
A number of members arriving early using a key to a door that creates a separate space. Maybe to form a social network, this tends to exclude other members of the group including the leader.

b. People coming late. Like the young man above who perhaps used his lateness to fulfil his need for attention or to be attacked.

\section{(ii) The language keys}

How language is used holds some basic keys. Deciphering the underlying meaning or metaphors can open particular doors.

a. Creative metaphors. A woman says, 'Well we haven't got tongues in our heads'. Explaining the problem for all the members of the group who were discussing the difficulties of getting people to listen to them, particularly about their emotions in relation to parents and authority figures. This metaphor was a key to the door of isolation, helplessness perhaps summarised in the same discussion by two men, one who insisted that 'nobody listens to us' and the other who is socially isolated full of anxiety about any relationship and explains that 'I prefer to play tennis with myself'. The group laugh at this metaphor with hints of bitterness and isolation in their voices. Another member comments 'it is a funny old world out there'.

b. Superego language. This is the language of what could be understood as a harsh operating super ego. The announcing of a supposedly normal moral stance which discloses hidden meanings and positions. Words like 'never', 'must', 'should', 'always', 'nobody' tend to come from an absolute, demanding, ruling super ego.

For example, A woman saying in a depressive voice 'I could never bake a cake like my mother'. The word 'never', if taken up, opens a door of unquestioned certainty, a dominant superego linked to the mother of the woman in this case.

c. Language mistakes, slips of the tongue. Freud's concentration on language in the Psychopathology of Everyday Life (Freud, 1901) and his theories on word presentation are classic illustrations of how language can be a key to uncover the unconscious to an undiscovered country.

For example, a man who was conceived to replace a much-loved daughter, previously killed in a road accident, was dressed and brought up as a girl in early childhood. Talking in the therapy group 
about his mother whom he has never been able to express anger towards, who he insists on idealizing said that 'she was the best thing since sliced breast' (he meant to say, as he explained, 'bread' and not breast). The group picked him up on this 'Freudian slip' with some initial laughter but with a growing recognition of the deeply internalized repressed emotion of anger and rage with his mother which he began to acknowledge over the following sessions with some relief and later with significant grief and sadness.

\section{(iii) Telling stories key}

Telling a story can be a key in itself

A general theme of not being looked after was present in a group after the absence of the therapists. One member told a story about how she had gone to a supermarket at 3 am and how useful she found this facility. She wondered why the rest of the world could not work on a 24 hour basis as well? Then she smiled and began to laugh, saying that maybe she expected a 24 hour service from the group or therapists as well. The whole group joined in the laughter using the key of the story to open up the space where their feelings of absent parents, the need for the ideal parent who would be always there, could be expressed. This story was referred to several times in later sessions.

\section{(iv) Humour key}

The examples of the language and the stories given above were often, as noted, accompanied with laughter. Laughter is part of the semiotic world of (Kristeva, 1980), the world of pre-language, the world of gestures, rhythm, prosody and word games. The importance of jokes as a key to open doors into the unconscious was pointed out by (Freud, 1905). We also think it serves as a release mechanism which increases the cohesiveness of the group in the space as well as improving the emotional insight of the members.

\section{(v) Position key}

A more overt key to an individual's relationship to the group is their positioning in the group.

a. Does the conductor always sit in the same chair? And if so how do the members react to that chair?

b. Are there arguments about who sits where? Is there a member who sits in the same chair all the time and insists on having it? 
c. Do they reposition their chairs? A man who had difficulty in all social relationships and felt superior to everyone constantly moved his chair back from the circle of the group.

d. The member who consistently sits opposite the 'authority' or another particular person in the group. For example, a man who always sat opposite the chair in meetings would object most of the time to any plans put forward in the organization. Who sits nearest to the door?

(vi) Sound key

a. When there is a constant babble about everything and yet nothing. This maybe suggests there is a door the group is afraid to open and to remark on this is a key which can reduce the fear.

b. When there is silence and again to remark about the difficulties of saying anything can be a key to open unmentionable doors.

(vii) Body language key

Turning away, looking away, facial expressions are important keys to what doors may be closing or opening.

(viii) Objects in the space and the space itself as key

The space itself or objects in it can become keys. For example:

a. Paintings. One young woman who constantly presented herself to the world as two totally different personalities could never sit opposite a print of Picasso's two faces of Dora Marr. This was remarked on by another member, a key to a whole discussion in the group of how we use 'different personalities' in dealing with different situations. A process which helped the woman to consciously integrate consciously her different personalities.

$b$. The whole space. A group who met in a room that was a former church tended to open doors linked to spirituality or Jungian themes.

\section{(1X) The ambient key}

To state the mood of a group can be a key moment in a group. The ambience, the pervading atmosphere, a tone, a feeling or a mood sometimes can be difficult to catch or pin down in a group. Artists often in their group depictions convey an intense sense of these different ambient moods. Austin Wright's sculpted group figures give a sense of this space and feeling. It is the oil for the hinges in opening 
the doors. It is more than the sum of all of the processes and occurrences within the space, more than the sum of the parts within it. We think that this ambience is the string that connects up Foulkes' nodal points, the net, the matrix, that holds the group together. One can consider the ambience of a group in the context of different keys.

a. Group development key. Awareness of how the group ambience has developed is an important key to understanding the group dynamics. Excitement and anticipation are often present in a new group, later there will be disappointment and lethargy, later still, acceptance, understanding of and the struggle of surviving. The curative factors of (Yalom, 1975), installation of hope, universality, imitative behaviour can help in observing these keys that are being used in the group and how far it has developed.

b. Orientation key. Freud's (Freud, 1921) thesis about groups noted that the leader and the libidinal attachment to the leader could be central to group life. It can dominate a group to such an extent that the group ignores reality e.g. the king with no clothes. A committee member saying to the Chief Executive 'nothing works very well when you are not here'.

c. The basic assumptions of Bion. All three of Bion's basic assumptions can infuse the mood of a group space which when pointed out at the appropriate time can be a powerful key to opening doors.

\section{Conclusion}

To conclude we think that the label on the door will tell us about the possible world of metaphors and ideas in the room behind the door. But no matter what type of group is occurring, the metaphors of doors and keys are helpful in understanding any group and these metaphors lead to a better understanding of group dynamics.

\section{ORCID iD}

Michael Scott iD https://orcid.org/0000-0001-5458-4935

\section{References}

Bion WR (1985) Group Dynamics: A Re-view. In: Klein M, Heimann P and MoneyKyrle R (eds) New Directions in Psychoanalysis Volume 130. London: Karnac, pp. 201-210, 421-431. 
Bowlby J (1978) Attachment and Loss. Harmondsworth: Penguin Books.

Bowlby J (1977) The Making and Breaking of Affectional Bonds. British Journal of Psychiatry 130: 201-210.

Derrida J (1967) 'Structure, Sign, and Play' in the Discourse of the Human Sciences. Writing and Difference, trans. Alan Bass. London: Routledge, pp 278-294.

Foulkes SH (1964) Therapeutic Group Analysis. London: Allen and Unwin.

Foulkes SH (1971) The Group as Matrix of the individual's Mental Life. In: Foulkes E (ed.) (1990) Selected Papers of SH Foulkes. London: Karnac.

Freud A (1937) The Ego and the Mechanisms of Defence. London: Hogarth.

Freud S (1910) A Special Type of Object Choice Made by Men. In: The Standard Edition of the Complete Psychological Works of Sigmund Freud Vol X1. London: Hogarth, pp. 171.

Freud S (1923) The Ego and The Id. SE VolX1X, pp 12-59.

Freud S (1901) The Psychopathology of Everyday Life. SE Vol VI.

Freud S (1905) Jokes and their Relation to the Unconscious. SE Vol VIII.

Freud S (1921) Is group psychology and the analysis of the Ego? Standard Edition, Vol. XVIII.Fromm E (1965) Socialist Humanism. New York: Doubleday and Co.

Read H, Fordham M and Adler G (eds) (1954) Jung CG (1953-78). In: The Collected Works of C G Jung. London: Routledge, pp. 801.

Klein M (1930) The Importance of Symbol-Formation in the Development of the Ego. In: Love Guilt and Reparation and other works 1921-1945. London: Hogarth Press.

Klein M (1946) Notes on Some Schizoid Mechanisms. In: Envy and Gratitude and Other Works. London: Hogarth Press, pp. 1-24.

Kristeva J (1980) Desire in Language: A Semiotic Approach to Literature and Art. Oxford: Blackwell.

Lacan J (1977) The Mirror Stage as a Formative Function of the I as revealed in Psychoanalytic Experience. In: Ecrits: A Selection Trans. Sheridan A London: Tavistock.

Lacan J (1977) The Four Fundamental Concepts of Psychoanalysis. Trans. Sheridan A. London: Hogarth Press.

Menzies IEP (1959) A Case Study in The Functioning of Social Systems as a Defence Against Anxiety: A Report On a Study of a Nursing Service of a General Hospital, pp 281-312. In: Colman A D and Bexton WH (1975) Group Relations Reader 1, AK Rice Institute Series. Goetz Printing, Springfield VA, USA.

Segal H (1957) Notes on Symbol Formation. The International Journal of PsychoAnalysis 38: 391-397.

Winnicott DW (1971) Playing and Reality. London: Tavistock.

Walshe J (1995) The External Space In Group Work. Group Analysis 28(4): 413-427.

Walshe J (2006) The Intermediate Space: The Border Country. Group Analysis 39(2): $185-197$.

Yalom ID (1975) The Theory and Practice of Group Psychotherapy. New York: Basic Books.

Michael Scott is a member of the Institute of Group Analysis (IGA), the Association for Psychoanalytic Psychotherapy in the NHS (APP) and the United Kingdom Council for Psychotherapy (UKCP). He was formerly a consultant 
adult psychotherapist in the NHS and is an honorary senior lecturer in the Department for Psychosocial and Psychoanalytic Studies at the University of Essex. He is also a psychotherapist and organizational consultant in private practice, and a leadership consultant and executive coach at INSEAD Business School, Fontainebleau, France. Address: 4 Orchard Place, Colchester CO4 5JW, UK.Email:scottm@essex.ac.uk

John Walshe studied medicine, neurology and psychiatry in Ireland. He is a fellow of the Royal College of Psychiatry. He is a group analyst and was formally the Medical Director of the NHS North East Essex Mental Health Trust and was the Consultant Psychiatrist in Psychotherapy in that trust. He is a founder member of the Centre for Psychoanalytical Studies and is presently an honorary senior lecturer in the Centre for Psychosocial and Psychoanalytic Studies at the University of Essex. His research interests are the use of space and language in psychotherapy. Address: 26 Creffield Rd, Colchester. Essex CO3 3HY, UK. Email:jhnwalsheI@gmail.com 